\title{
A mulher no teatro da República
}

\section{Fernando Matos Oliveira}

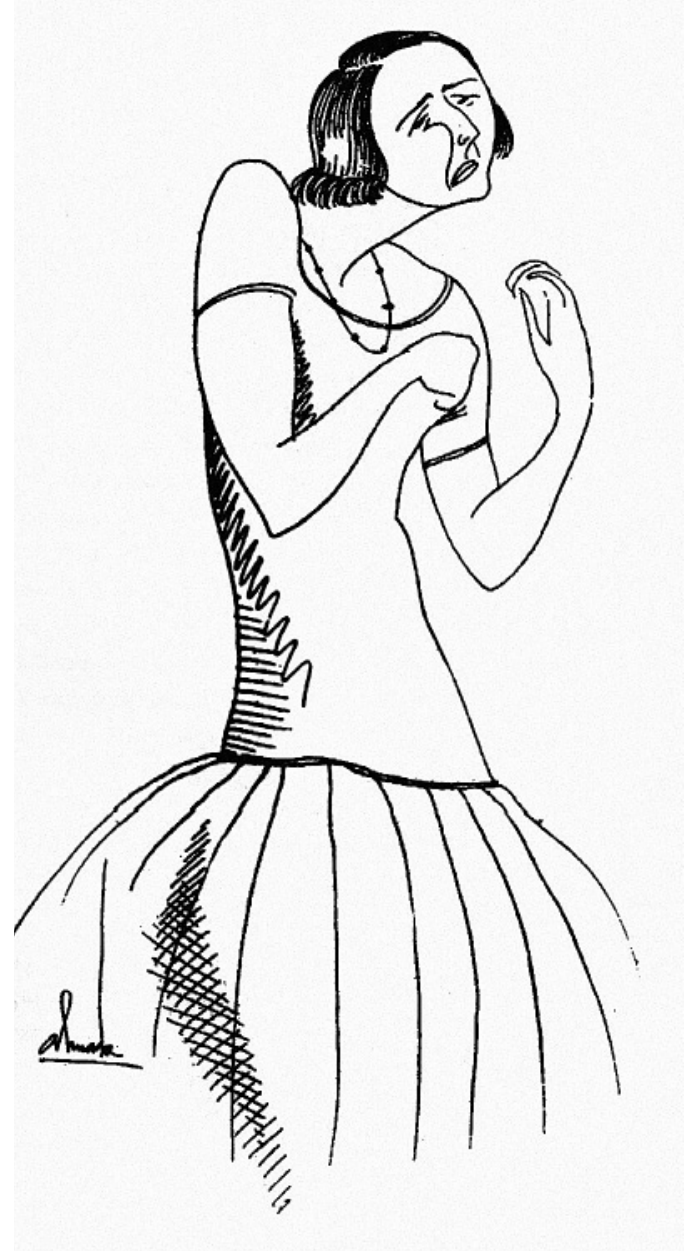

1.

A possibilidade mesma de se pensar especificamente a mulher no teatro da República supõe a existência de um vinculo entre a condição feminina e o projecto republicano em Portugal. Na verdade, desde a fundação da Liga Republicana das Mulheres Portuguesas, em 1908, até ao ano de 1926 desenvolveram-se inúmeros movimentos associativos, patrocinados por um conjunto de mulheres determinadas em inverter o estatuto subalterno que historicamente as limitava, tanto na esfera privada, como na esfera pública.

Dispomos hoje de um conjunto significativo de estudos sobre os vários momentos desta aventura, descrevendo em detalhe as hesitações e os avanços no processo de emancipação da mulher ao longo do nosso Séc. XX. Um dos aspectos que marcaram esta deriva, no que ao período da $1^{\text {a }}$ República diz respeito, consistiu na sobreposição entre as componentes feminista, maçónica e propriamente republicana. Apesar da desagregação da Liga Republicana e do trajecto diferenciado que a partir de 1910 as suas protagonistas empreendem - originando a Associação de Propaganda Feminista (1911-1918), a Associação Feminista de Propaganda Democrática (1915) ou o Conselho Nacional das Mulheres Feministas (1914-1947), entre outras agremiações -, as mulheres portuguesas coincidem fundamentalmente numa agenda que contemplava aspectos tão decisivos como o direito à instrução, o direito ao trabalho, o direito à administração dos bens, além do combate à mendicidade infantil e a todas as formas de marginalização social baseadas no género. Como sumaria João Esteves, "em momentos únicos ou banais, as mulheres estiveram lá. Pensaram, debateram organizaram-se, actuaram. Escreveram, opinaram, polemizaram (...) Marcaram presença em sessões, reuniões, festas, saraus, comícios, congressos, homenagens, celebrações, cortejos, manifestações, funerais, romagens. Foram para a rua" (Esteves 2008:24).

0 discurso que Ana de Castro Osório profere na sessão inaugural da Liga Republicana das Mulheres Portuguesas, em 28 de Agosto de 1908, ilustra tanto o vínculo republicano que a sua geração assume claramente, como as enormes expectativas que viriam a desaguar no ano de 1910

\footnotetext{
A república, minhas senhoras, não sendo uma forma de governo

nova nem perfeita - porque não há nada que em absoluto o seja é no entanto a mais lógica, mais compreensivel à nossa inteligência e mais tolerável à nossa razão, dando-nos também mais garantias de progresso.

Acusam-nos alguns porque aceitamos a república e fazemos a sua propaganda, nós as mulheres, que nada devemos aos governos nem aos legistas. E perguntam-nos com indignação: '0 que nos importa a forma de governo?...'

Importa-nos muito, porque estamos dentro da sociedade, dentro da lei, dentro das convenções e a maioria não quer nem pode sair desses limites. Importa-nos e interessa-nos a república portuguesa porque só ela nos pode fazer o que a Monarquia nem sequer se atreve a admitir em pensamento.
}

Mulheres como Ana de Castro Osório, Adelaide Cabete Maria Veleda ou Carolina Beatriz Ângelo pugnaram pela transformação da sociedade portuguesa, sabendo conjugar a demanda idealista que em 1909 exigia ainda a libertação de todos os "escravizados" - como afirmavam em missiva enviada ao Congresso de Setúbal, organizado no mesmo ano pelo Partido Republicano -, com o espírito de compromisso que a realidade política inaugurada a 5 de Outubro viria a exigir. Com efeito, logo após a instauração
Desenho de Almada Negreiros para Zilda de Alfredo Cortez. 
da República, uma delegação da Liga cumprimenta o Governo Provisório e integra nos anos seguintes reuniões sucessivas com diversos ministros e responsáveis políticos, em prol do reconhecimento da mulher como sujeito com direitos civis iguais ao homem, que continuava efectivamente a tutelar a vida pública.

0 tempo da República é portanto o momento de passar da reflexão à prática, mas é também o momento decisivo do confronto entre o ideário feminista e a entropia do tempo português, numa sociedade fortemente marcada pelo ascendente do patriarcado católico e pelas dificuldades em sustentar ou sequer compreender a urgência da igualdade de direitos ou a laicização dos costumes que 0 pensamento republicano integrava.

2.

0 teatro, como a arte em geral, participa naturalmente deste ambiente politico e confronta-se com iguais paradoxos. Logo no primeiro número do Eco artístico, uma prolífica revista teatral que atravessa este período (19111920), Bento Faria assina um texto intitulado "0 teatro e a questão social". Dando por adquirida a revolução política, pedindo a revolução económica e sugerindo, enfim, um novo comprometimento cívico do drama, Bento Faria destaca as vantagens comunicativas do teatro relativamente às artes descritivas:

No presente momento histórico em que parece estar resolvido o problema político em Portugal pela implantação da República e em que, por consequência, ressalta a necessidade de cuidar mais especialmente do problema económico, julgo oportuno e de interesse lembrar quanto de relação existe entre a literatura dramática e a questão social, como factor de propaganda dos modernos principios filosóficos (...)

Se na literatura meramente descritiva se obtém o ensinamento de que depende o futuro dos povos, pelo teatro esse ensinamento será muito mais proveitoso, porquanto se faz perpassar nos olhos do público as figuras vividas, essas mesmas figuras que dia a dia, hora a hora, vemos cruzar no meio social e que são a origem do conflito da vida (...)

0 teatro não poderá ser tomado exclusivamente como simples distracção. 0 seu fim é instruir educando. (Eco Artístico, №. 1, pp. 2 -3)

Estas declarações recuperam a pedagogia cívica herdada do programa iluminista, que sustentou tanto a acção de Lessing no teatro de Hamburgo, como a declinação nacional que Garrett Ihe confere no romantismo lusitano, no início de Oitocentos. A necessidade desta reafirmação, numa revista que se propunha filtrar pela crítica "honesta" todo o movimento teatral da nação republicana, revela a persistência de um problema que se arrastava desde longa data. É fácil constar que paira de facto uma sombra persistente sobre o teatro português, entre o diagnóstico severo de Garrett, o criticismo da Geração de 70, a censura acutilante de Fialho de Almeida e as tentativas de renovação, empreendidas a partir de 5 de Outubro.

Como demonstraram Glória Bastos e Ana Isabel Vasconcelos, no volume intitulado 0 teatro em Lisboa no tempo da República, apesar dos esforços mais ou menos intermitentes, a cultura teatral dominante manteve-se sem grandes oscilações; o ímpeto renovador que começou por arejar o Teatro Nacional e a Escola da Arte de Representar não foi suficiente, por falta de massa crítica e de critério selectivo, para produzir uma alteração substantiva nas práticas instaladas. Tratando-se de um estudo documentado e atento à dimensão plural do espectáculo, a sintese apresentada neste trabalho descreve com detalhe as várias facetas de um processo de "evolução na continuidade". Em boa medida sobrevivem à República reportórios, tipologias espaciais, estilos de interpretação e dinâmicas da recepção do espectáculo, além da permanência óbvia do elenco de actores.

Isto mesmo é confirmado nos jornais e nos periódicos da especialidade. A representatividade do Eco artístico é a este respeito notória, ao assinalar a redundância de um género como a revista - o espectáculo ao vivo que despertava maior interesse público -, as deficiências na formação de actores, a debilidade da produção dramática nacional, a corrida ao último sucesso em Paris ou em Londres e as inúmeras tricas que agitavam o meio teatral patentes no conflito frequente entre os interesses de empresários, actores e público.

0 público, justamente, teimava em manter a pateada como manifestação legítima do gosto e continuava a interromper amiúde os espectáculos. Tardava, pois, a cultura da escuta que por esta altura a própria encenação emergente dava sinais de preferir, ao experimentar o escurecimento progressivo da sala, a bem da ilusão teatral ${ }^{2}$.

3.

Se olharmos para a vida teatral no período da República atendendo especificamente ao papel da mulher e às representações do feminino, devemos referir, antes de 


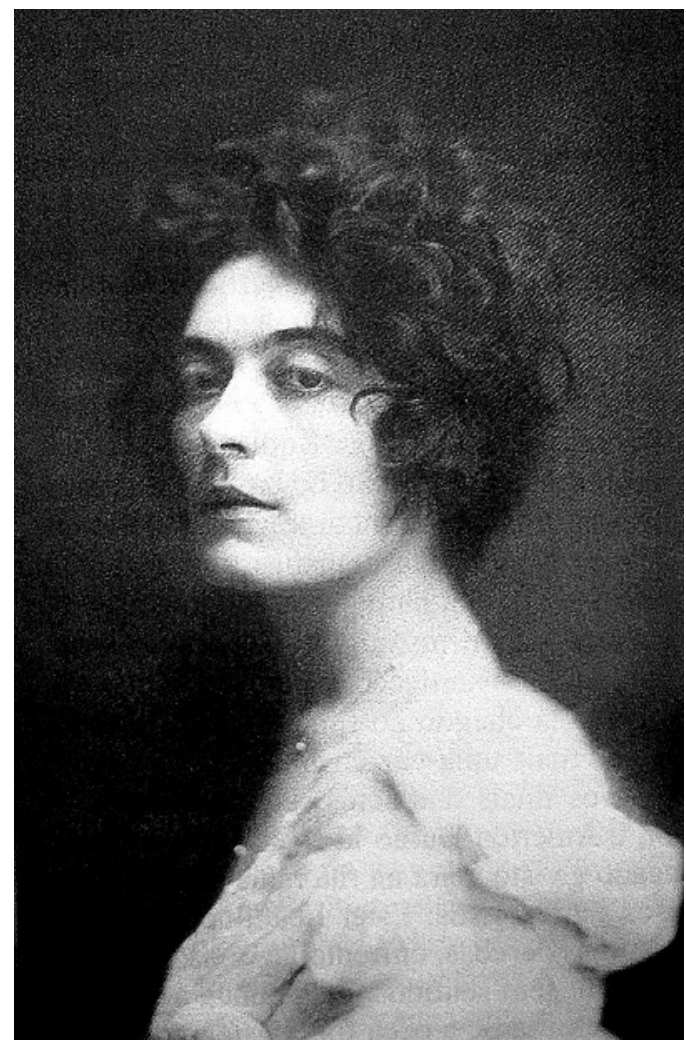

tudo, a situação da actriz, que se mantém num território condicionado, dividida entre a aclamação e a rejeição, a formatação necessária aos papéis estereotipados que o reportório dominante Ihe impõe e a fragilidade social associada ao seu estatuto. A Associação de Classe dos Artistas Dramáticos, criada em 1908, quando se multiplicam os efeitos do associativismo pré-revolucionário, não mudaria grandemente este estado de coisas. A contingência inerente à profissão, sendo de sempre, subsiste mesmo numa actriz com a ascendência de Ester Leão, filha do republicano Eusébio Leão, diplomata que chegou a marcar presença na varanda da Câmara Municipal de Lisboa, aquando da Proclamação. A pequena monografia que João Florindo dedicou ao trajecto desta singular actriz, com o título Ester Leão. Uma actriz da República, dá conta do preconceito associado à carreira teatral e descreve os dilemas que se colocavam a uma mulher (e a uma actriz) com espírito demasiado inquieto. Tanto assim era que a própria família terá tentado, mediante encomenda de uma pateada, boicotar a sua estreia como protagonista na peça 0 assalto (1913), de Henri Bernstein, onde contracena com Augusto Rosa (cf. Florindo 2010: 30).

Mais frágil se apresenta a escrita para teatro de autoria feminina, facto na verdade extensível a outros géneros e não muito divergente da realidade ibérica coeva. No entanto, os dados recolhidos por Eugénia Vasques, contabilizam surpreendentemente cerca de cinquenta dezenas de autoras com textos identificados no período que medeia entre 1900 e 1929 (cf. Vasques 2001). A presença auspiciosa de uma dramaturga no Teatro Nacional, no primeiro ano da centúria, acabará por se revelar uma excepção nas décadas seguintes. A primeira agonia, peça de Caïel (pseudónimo da pedagoga Alice Pestana), ao tematizar o sacrificio materno, prova contudo que o acesso pleno à experiência do feminino não pode ser delegado sem perdas nos dramaturgos

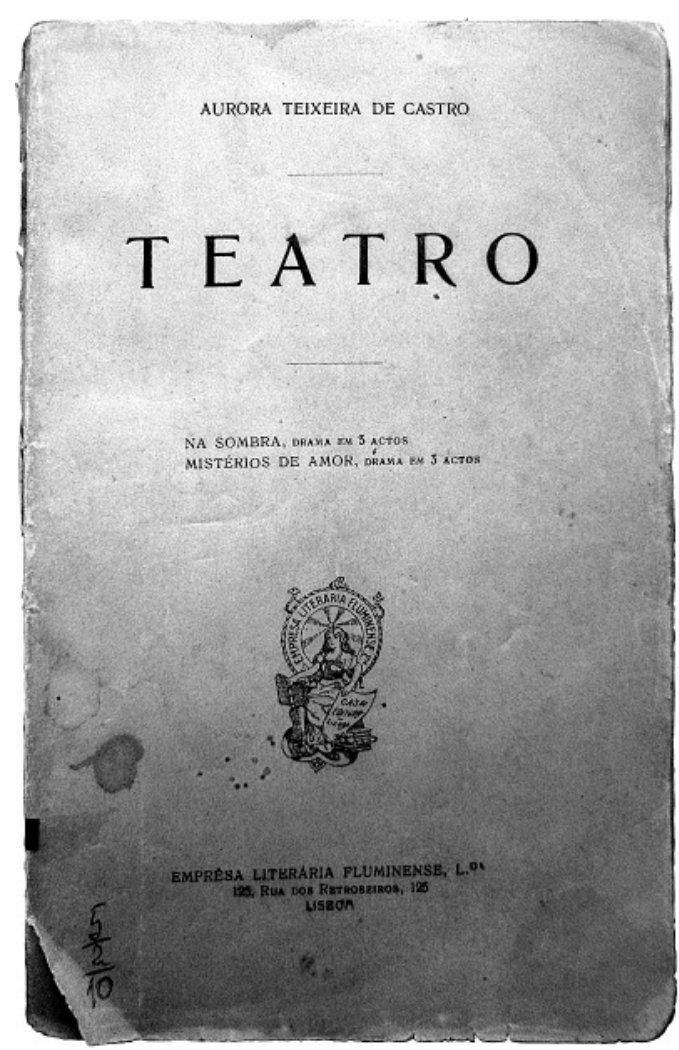

Ester Leão, 1921

[Cortesia do MNT].

Capa do livro de

Aurora Teixeira de Castro Teatro, Lisboa, Empresa Literária Fluminense, 1927.

masculinos, que por sua vez começavam a contemplar mulheres de nova espécie na escrita para teatro.

A maior parte dos textos escritos por mulheres replica a galeria social da pequena comédia de costumes, revelando-se por vezes como tentativas dramáticas incipientes ou então alimentando o teatro para a infância, em muitos casos, pela mão das mulheres que empreenderam o trabalho educativo da República, como foi o caso de Alice Moderno, feminista precursora e também dramaturga ocasional. Ana de Castro Osório, Angelina Vidal ou Clotilde Carreira são alguns dos nomes que nesta década escrevem para a infância.

\section{4.}

0 caso de Aurora Teixeira de Castro ilustra o "drama de tese" que ao tempo serviu bem a prédica republicana. Este género dramático ganha força por via de traduções como a que o Teatro República leva à cena, em 1912, intitulada 0 apóstolo, onde a laicização do ensino é questão em debate, ou ainda através de autores nacionais, como seria o caso de Augusto de Lacerda, autor de Os mártires do ideal (1915) e de Os novos apóstolos (1916).

Tendo sido um género cultivado por autores (masculinos), no drama em 3 actos intitulado Na sombra, Aurora Teixeira de Castro distribui pelas personagens todo um programa de acção, onde não faltam declarações sobre as práticas educativas assentes na literatura, na educação física ou na educação religiosa; reflexões sobre a

divergência entre um ensino literato e um ensino aberto às ciências naturais ou ainda a reafirmação do direito de homens e mulheres a igual instrução.

A autora produz inclusive inversões curiosas, como sucede quando coloca na voz de homens a defesa dos mais importantes princípios feministas. 0 texto beneficia claramente da intensa participação da dramaturga em 
actividades feministas e pedagógicas das primeiras décadas do século XX. Na edição de 1927, apresenta-se inclusive no verso da capa como autora de conferências com títulos tão reveladores como os seguintes: "Reivindicações sociais e políticas da mulher portuguesa na República" e "Influência da educação na vida psicológica do homem".

0 seu perfil intelectual explica também a presença no drama de tópicos realmente "adiantados" no tempo, como o dever da partilha da educação dos filhos por pais separados. Insiste também em temas caros à agenda liberal, contrastando a abertura do ensino doméstico com o aprisionamento mental praticado nos colégios. No primeiro acto, Gilberto Ramires confessa ao amigo Artur Ramalho:

Detesto a educação colegial; quase sempre as crianças se deformam lá. Ou se preocupam somente com a educação literária e a criança fica enfezada ou se preocupam em demasia com a educação fisica e a criança nada aprende de basilar e de sólido, acrescendo a tudo isto um cortejo de defeitos morais que lá adquire e de que não é fácil emancipar-se pela vida fora. ${ }^{3}$

A educação desagua inevitavelmente na questão religiosa. 0 sobressalto destas ideias, que alguém afirma serem próprias de "pedreiros-livres", leva a que Leonor, a personagem de tendências católicas e tradicionalistas, se movimente no sentido de criar também para si uma agremiação protectora, com o nome algo jocoso de "Associação Escudo Cristão"!

Além dos textos para a infância, num balanço abreviado, dir-se-ia que a escrita feminina para teatro oscila assim entre o drama que promove a pedagogia civica e textos que celebram certa intimidade/domesticidade feminina, quase sempre misturada com desventuras amorosas assaz convencionais. Quando muito, tais desventuras comportam a reivindicação do direito à escolha do noivo, como termina por dizer a personagem Lena, no drama Uma história de boneca, escrito por Ester de Leão para a festa da actriz Constança Navarro, no Teatro Politeama, em 1923: "É o meu noivo. Mas este agora é verdadeiro. Foi escolhido por mim."

5.

${ }^{3}$ Aurora Teixeira de Castro, Teatro, Lisboa,

Empresa Literária Fluminense, 1927, p. 28.
A laicização do casamento constitui um dos fenómenos centrais na evolução dos costumes e no programa emancipatório do período republicano. A sujeição da mulher data do ordenamento proposto pelo Código Civil, sobretudo nos anos de 1865 a 1866. 0 casamento civil passa então a ser uma opção mas, como informa Fernando Catroga, não se tratava ainda de uma proposta "manifestamente laica", pois não se impunha e também não se reconhecia o direito ao divórcio (cf. Catroga 1986: 6). A ordenação jurídica de meados de Oitocentos consagra a sobreterminação masculina e impõe à mulher um enorme catálogo de interdições, que apenas um século depois viriam a cair na sua totalidade. 0 avanço lento do casamento civil, por exemplo, mostra como foi dificil entre nós a construção da unidade secular do estado-nação e como persistiu até muito tarde a força concorrente da ritualidade católica.

A questão da mulher torna-se, pois, decisiva apenas no início do séc. $X X$, precisamente quando a densificação das classes urbanas, alfabetizadas e mais disponiveis para a contratualização laica, submete o velho Código Civil a um derradeiro teste de resistência. 0 feminismo português nasce neste contexto e a reivindicação do direito ao divórcio torna-se numa das causas mais emblemáticas das mulheres, tal como a reivindicação do direito de voto. Em 1910 publicam-se as leis do divórcio e da família e no ano seguinte, não por acaso, torna-se obrigatório o registo civil, condição absoluta para a construção de um poder centralizado e laico: o registo civil instituía cada sujeito como cidadão.

No último terço do séc. XIX, o que estava em pauta era ainda a percepção do casamento civil e do casamento católico como alternativas legítimas. Com efeito, este é ainda o tema de uma débil peça de Cipriano Jardim, intitulada Casamento civil, representada no Teatro Nacional no ano de 1882. Nas duas primeiras décadas do séc. $X X$ o teatro confronta já de modo insistente o divórcio, que então se converte num assunto omnipresente no palco, tal como a questão feminina em geral, pelas razões expostas. A oportunidade que se abre em 1910 é portanto a de dar expressão pública (e política) a um conjunto de aspectos que vinham sendo anunciados ou amadurecidos num periodo em que se sobrepõem a desagregação da Monarquia e a construção da República.

0 Teatro Nacional acolhe dois espectáculos sobre a questão do divórcio. Em 1890 apresenta em tradução a comédia As surpresas do divórcio, um original de Alexandre Bisson e Anthony Mars. Vinte anos depois, o divórcio passa literalmente de surpresa a Lei e dá título ao espectáculo - A lei do divórcio - que Augusto de Lacerda escreve com grande impacto público e político para a mesma casa, 
com a presença de Afonso Costa e de Bernardino Machado entre os espectadores.

No entanto, a publicação da Lei não significava a aceitação universal do divórcio, nem a normalização da questão feminina no seu todo. 0 estatuto da mulher permanece em negociação, a ponto de, já em 1911, um articulista se referir à comédia Os direitos da mulher como "assunto estafado" ${ }^{4}$. Com autoria de Arthur Cohen e Guiherme Barbosa, o espectáculo no Teatro do Ginásio é descrito como uma "crítica ao feminismo".

0 que ressalta da observação do reportório deste período é a persistência desta temática e a sua perspectivação sob diversos ângulos, dependendo de um posicionamento mais próximo do campo liberal ou do campo conservador. Podemos assim ver como Ramada Curto, prolífico dramaturgo do tempo da República, apresenta em 1920, na Câmara dos Deputados, uma moção que previa o sufrágio feminino, que no entanto não chega a ser votada. Já em 1922, no referido drama de Aurora Teixeira de Castro, o diálogo entre as personagens Domingos Moreira e Gilberto Ramires denota a actualidade da questão:

DOMINGOS - Mas, por muito ampla que seja a instrução da mulher, na minha opinião, ela nunca poderá prescindir do auxilio do homem, porque é ele o forte.

GILBERTO - Forte é o que tem mais valor. Tanto no casamento como fora do casamento, a mulher pode muito bem prescindir desse auxilio, conseguindo a sua independência pelo seu trabalho e pelo seu esforço (...)

DOMINGOS - 0 Ramires é um feminista entusiasta..

LEONOR - Mas é com essas doutrinas e com esses entusiasmos que os senhores 'avançados' têm arrastado as mulheres para a libertinagem. Desde que a mulher deixou de ser o anjo do lar...

Noutros textos, a agitação deste periodo e a reconfiguração mais ou menos violenta dos valores herdados, conduzem o teatro a discursos moralizadores ou quase maniqueístas sobre a mulher. A comédia e a opereta expõem de forma mais imediata esta ansiedade, em títulos que funcionam como reclames de um tempo que passou: A mulher eléctrica (1909), A mulher moderna (1910), Mulher artificial (1921) ou A mulher nua (1925).

\section{6.}

0 cinema cresce como arte de grande impacto público com a República e contribui também para o contacto crescente com experiências divergentes do feminino. É também de considerar seriamente o vínculo entre 0 processo de laicização e a pluralização das representações da mulher, dando origem a um conjunto singular de figuras femininas, com presença no teatro, mas também na poesia e na narrativa, contextos em que actua com maior impacto a produção modernista e vanguardista, pouco expressiva no palco da época.

Sabina Freire, de Manuel Teixeira-Gomes, inaugura de certo modo esta galeria nova de mulheres que, mediante uma espécie de contraste de género, denunciam a pátria como "terriola" preconceituosa e mal frequentada. Esta deriva nem sempre se caracteriza por um sentido unívoco ou claramente emancipatório, já que a autoria masculina que as anima tende à objectificação erótica, como sucede com Almada Negreiros, por exemplo. Existem, pois, diferenças mais ou menos acentuadas entre Sabina Freire (1905), A leviana (1921) de António Ferro, a Judite que Almada Negreiros anuncia com 0 nome de guerra (1925), a vida marginal da Zilda (1921) de Alfredo Cortez, ou a ambígua "confraternização mental feminista" que antecede o vigésimo matrimónio da Protagonista, em Os gladiadores (1934), peça em registo grotesco do mesmo autor.

As peças Zilda (1921), de Alfredo Cortez, e Mar alto (1922), de António Ferro, apresentam-nos duas mulheres marcadas por uma atracção irracional pelo fútil. Trata-se de duas mulheres vitimadas por jóias e vestuário, territórios que de algum modo somatizam a monetarização da vida urbana e a pulsão fetichista que advém da convivialidade artificiosa. Não surpreende que ambas as peças tenham sido incompreendidas e mesmo censuradas no tempo da sua representação.

Gostaria contudo de encerrar esta visitação com uma referência mais alongada a Sabina Freire, nome de uma personagem feminina que nas vésperas da República denuncia o atavismo local e prenuncia com uma liberalidade inaudita o tempo por vir. Teixeira-Gomes, como é sabido, assumiu a arte como operador privilegiado da redenção humana. Apreciar significa para este autor que viria a ser o sétimo Presidente da Primeira República Portuguesa, antes de tudo, aprender a olhar, dominar a velocidade necessária à incorporação sensivel das coisas e dos seres, em movimento lento e contínuo. Eis o que escreve a Columbano: "O primeiro mês da minha viagem ${ }^{4}$ Eco Artistico, foi todo em perpétuo mobile - cinematográfico (...) em № 1, 1911, p. 5 . todos os ramos das belas-artes e letras o essencial é poder, é saber 'ver'" (Teixeira-Gomes 1989:162). Apreciar 
propriamente a vida e a arte configura uma equação que ao tempo haveria de orientar toda uma estratégia de nobilitação posta em marcha pelo patriciado burguês republicano. Acresce que a soberania da arte negava qualquer autoridade à moral, considerada como o maior obstáculo, perante o mesmo Columbano: "0 último, o inexpugnável reduto dos inimigos da beleza, aquele onde eles se entrincheiram vitoriosamente, para dai condenar às penas máximas os grandes artistas rebeldes, é a moral". (Ibidem:135)

Ora, a vontade de viver que move a personagem Sabina Freire recusa assim o esteticismo de tipo decadentista e aproxima-se antes da corporeidade livre que a tradição jacobina e vitalista admirava. Casada com Júlio Freire, um poeta lírico de velha cepa lusitana, transplantada de Paris para a rusticidade do Algarve em finais de Oitocentos, Sabina ilustra a referida capacidade de apreciação, mas promove também uma verdadeira inquirição à cultura de chegada, esmiuçando a um tempo o território e as mentalidades que vem encontrar.

Neste processo de inquirição feminina deve reconhecer-se que apesar de um ou outro excesso palavroso, mormente em alguns solilóquios, a análise resistiu notavelmente à prova do tempo. Veja-se, a este propósito, o diálogo entre Sabina e o Doutor Fino sobre a ascensão da figura do médico em Portugal. Além de secularizar o antigo ofício das almas, observamos como em termos históricos o médico se despede por completo do tempo em que "barbeavam e monopolizavam a aplicação dos clisteres", passando a beneficiar de um ascendente assaz bacoco em contexto doméstico: "Implantou-se aqui a hierarquia da doença competindo com a hierarquia social da fortuna e do sangue" (Teixeira-Gomes 1987:25). Esta referência à mania de falar de doenças metaforiza assim a própria patologia das elites locais, bem como a patologia do espaço público e conversacional. A nação tende à sociabilidade mesquinha da casa de D. Maria Freire, uma provinciana somítica e retrógrada. A este pequeno mundo não faltará sequer Ministro, vénias e baile ao Segundo Acto.

0 próprio registo cómico que domina a peça compreende-se melhor no âmbito da pedagogia do riso. A critica seguramente desejaria ver nesta Sabina o registo sério de uma Hedda Gabler, com quem aliás a personagem partilha autonomia, maquinação e apetência criminosa. No entanto, o mundo boçal e os desmandos retóricos dos conterrâneos legitimam a estratégia risivel que Teixeira Gomes enfatizou nesta comédia em três actos. Não há de facto comicidade fora do que é humano: são vários os momentos nos quais a ironia e a paródia servem o rastreio impiedoso dos costumes e dos hábitos, ou mesmo a denúncia de "excelentíssimos pedaços de asnos", como são qualificados Epifânio e Augusto César. Abundam os momentos de ironia, o cómico de situação, as insinuações hilariantes, além de tiradas melodramáticas provindas de um marido "empapado de luar" e incapaz de agir com tino.

0 dramaturgo manifesta domínio sobre o seu meio expressivo e não raras vezes revela a percepção metateatral que define o olhar exterior a que tende o risivel da comédia: Júlio anda "hamlético", o léxico conceptual contamina o diálogo teatral e insinuam-se "cenas dramáticas" e "tragédias gregas". A linguagem e a estruturação do texto de Teixeira-Gomes precedem a experimentação formal e mimética do modernismo. Neste âmbito, o próprio autor privilegiou claramente o pathos expressivo e a legibilidade da fábula, colocando-as ao serviço de uma mulher possuída pelo "encanto de viver", a todo o custo, com ou sem venenos adicionais, aquém a além da República.

\section{Referências bibliográficas}

BASTOS, Glória / VASCONCELOS, Ana Isabel P. Teixeira de (2004), 0 teatro em Lisboa no tempo da Primeira República, Museu Nacional do Teatro / IPM.

CATROGA, Fernando (1986), "A laicização do casamento e o feminismo republicano", Sep. de A Mulher na Sociedade Portuguesa - Actas do Colóquio, Coimbra.

ESTEVES, João (2008), Mulheres e republicanismo (1908-1928), Lisboa, Comissão para a Cidadania e a Igualdade de Género.

FLORINDO, João M. A. (2010), Ester Leão. Uma actriz da República, Gavião, Ramiro Leão.

LEAL, Maria Ivone (1992), Um século de periódicos femininos. Arrolamento de Periódicos entre 1807 e 1926, Lisboa, Comissão para a Igualdade e para os Direitos das Mulheres.

REBELLO, Luiz Francisco (1989), História do teatro português, Lisboa, Europa-América.

TEIXEIRA-GOMES, Manuel (1987), Sabina Freire, Lisboa, Bertrand Editora. -- (1989), Cartas a Columbano, Lisboa, Bertrand Editora.

VASQUES, Eugénia (2001), Mulheres que escreveram teatro no século XX em Portugal, Lisboa, Colibri. 